\title{
INTERNALISASI NILAI-NILAI TASAWUF DI PONDOK PESANTREN AL-AMIEN PRENDUAN
}

\author{
Andri Sutrisno \\ Institut Dirosat Islamiyah al-Amien (IDIA) Prenduan Sumenep \\ Andrisutrisno1993@gmail.com
}

Abstrak

Ilmu tasawuf merupakan suatu ilmu yang mengutamakan diri manusia agar memiliki kebersihan ruhani dan jiwa. Di Pondok Pesantren al-Amien Prenduan menanamkan nilai-nilai yang ada dalam ilmu tasawuf. Hal ini bertujuan agar para santri selalu taat pada perintah Allah Swt. dan memiliki nilai-nilai persatuan antar-sesama santri. Penelitian ini menggunakan pendekatan kualitatif deskriptif dengan jenis penelitian lapangan. Adapun metode pengumpulan data menggunakan observasi, wawancara, dan dokumentasi. Data tersebut kemudian dianalisis dengan reduksi data, penyajian data, dan penarikan kesimpulan. Hasil penelitian ini menunjukkan, pertama, proses internalisasi nilai-nilai tasawuf melalui nilai Ilahi dan nilai insani di Pondok Pesantren al-Amien Prenduan; kedua, bahwa faktor pendukung dalam internalisasi nilai tasawuf melalui upaya pendampingan pendidikan selama 24 jam dan suri tauladan yang baik oleh para kiai dan para guru. Sedangkan faktor penghambat internalisasi tersebut antara lain para santri masih banyak yang melanggar disiplin pondok dan karena latar belakang keberagaman suku yang berbeda-beda baik dari Jawa, luar Jawa atau bahkan dari luar Indonesia.

Kata Kunci: Internalisasi Nilai, Tasawuf (Sufisme), Pondok Pesantren, al-Amien Prenduan. 


\section{Abstract}

Sufism is a science that prioritizes human beings in order to have the cleanliness of the soul and spirit. In the boarding school Al-Amien Prenduan instilled the values that exist in the science of Sufism. The goal is for the students to always obey the command of Allah Almighty and have the values of unity among fellow students. This study uses a descriptive qualitative approach to the type of field research. The data collection method uses observation, interview and documentation. Then the data is analyzed with data reduction, data presentation and conclusion withdrawal. The results of this study show that: 1) the process of internalization of the Sufism values in boarding schools through divine values and human values; 2) supporting factors in internalizing the value of Sufism with the assistance and education for 24 hours and good suri tauladan from the kiai and teachers. While the inhibitory factor is among the students are still many who violate the discipline of the cottage and because of the background of diversity of different tribes both from Java, outside Java or even outside Indonesia.

Keywords: Internalization of Values, Sufism, Boarding School, al-Amien Prenduan.

\section{Pendahuluan}

Krisis manusia modern seperti yang juga terjadi pada lingkungan hidup dan kehidupan modern bermula dari krisis ketidakpercayaan, yang dalam bahasa Nasr, pemberontakan terhadap Tuhan. Pemberontakan ini merupakan akibat dari paradigma zaman pencerahan yang rasionalistik, positivistik, dan antroposentris. ${ }^{1}$

Kini persoalan manusia semakin berubah seiring berkembangnya mode interaksi manusia. Tidak hanya dunia digital dan komunikasi informasi, produk rasionalitas kontemporer juga telah mampu menghasilkan kecerdasan

1 Hossein Nasr, Islam dan Nestapa Manusia, ed. by Anas Mahyuddin (Bandung: Pustaka Mulia, 1983). buatan atau artificial intelligent. Namun, kecerdasan dan perkembangan ini justru cenderung menambah krisis kemanusiaan. Perilaku manusia modern yang pandai tidak menjadi lebih manusiawi. Bahkan, fenomena ini membenarkan bahwa manusia memang semakin jauh dari Tuhannya.

Oleh karena itu, sudah seharusnya berbagai persoalan tersebut menjadi memperhatikan pondok pesantren sebagai lembaga pendidikan Islam, penghasil manusia-manusia Muslim. Dalam artikel ini peneliti meneliti persoalan internalisasi pengajaran nilai, khususnya ilmu tasawuf, dalam Pondok Pesantren al-Amien, Prenduan, Sumenep, Jawa Timur, yang sudah dikenal luas tidak hanya di Jawa Timur, tetapi juga dari 
Asia. Selain karena faktor kemasyhuran pondok pesantren ini, yang menarik untuk dikaji adalah bahwa pondok pesantren ini juga dikenal dengan ilmu tasawufnya. $^{2}$

\section{Internalisasi Nilai-Nilai Tasawuf}

Istilah internalisasi nilai dapat dipahami sebagai peresapan kembali realitas produk aktivitas oleh manusia dan mentransformasikannya dari struktur objektif ke dalam struktur subjektif. ${ }^{3}$ Jadi, internalisasi nilai-nilai tasawuf berarti suatu peresapan ajaran-ajaran Ilahiah ke dalam hati manusia yang diwujudkan manusia dalam perilakunya sebagai realitas.

\section{Santri dan Pondok Pesantren}

Istilah pesantren berasal dari kata santri; pe-santri-an. Secara sederhana, santri dapat dipahami sebagai orang yang mempelajari ajaran agama Islam di suatu tempat yang disebut pesantren. Pesantren disebut juga dengan surau di daerah Minangkabau, penyantren di Madura, pondok di Jawa Barat, dan rangkang di Aceh. ${ }^{4}$

Dalam bahasa Arab, kata pondok dekat dengan kata funduq yang artinya

2 Iwan Kuswandi, KH. Muhammad Idris Jauhari: Sang Konseptor Pendidikan (Yogyakarta: Ladang Kata, 2015).

3 Peter L. Berger, Langit Suci, ed. by Muhaimin (Yogyakarta: Rosdakarya, 2001).

\footnotetext{
4 Kuswandi, KH. Muhammad Idris Jauhari.
}

hotel atau asrama. Pondok pesantren dipahami sebagai tempat belajar para santri. Jadi, pondok pesantren didirikan karena adanya kesadaran dalam membentuk kader-kader ulama dan da'i, serta sebagai tuntutan dan kebutuhan zaman terhadap dakwah Islamiah. ${ }^{5}$

Menurut salah satu tokoh pendiri Pondok Pesantren al-Amien Prenduan, Muhammad Idris Jauhari, pondok berarti tempat tinggal, sedangkan pesantren berasal dari kata penyantrian yang artinya tempat santri atau proses menjadi santri. ${ }^{6}$ Jadi, dari uraian tersebut dapat dipahami bahwa pondok pesantren berarti tempat tinggal santri dalam rangka untuk beribadah dan mencari ilmu bersama dengan kiai panutan dalam keseharian mereka.

\section{Nilai-nilai Ajaran Tasawuf}

Menurut Kiai Jauhari, tasawuf adalah perwujudan ajaran Islam pada aspek Ihsan-tanpa menihilkan aspek Iman dan Islam sebab ketiganya satu kesatuan. $^{7}$ Hal ini sejalan dengan tujuan mempelajarinya, yakni sebagai penghayatan ajaran Islam yang bersumber dari

5 Achlami HS, "Internalisasi Kajian Kitab Akhlak Tasawwuf dan Pendidikan Karakter di Pesantren Al-Hikmah Bandar Lampung," Analisis: Jurnal Studi Keislaman 18, no. 1 (2018), https://doi.org/10.24042/ajsk.v18i1. 3302.

${ }^{6}$ Muhammad Idris Jauhari, Anak Muda Menjadi Sufi, Mengapa Tidak? (Sumenep: AlAmien Printing, 2003).

7 Jauhari. 
al-Qur'an dan Hadis Nabi Muhammad Saw. ${ }^{8}$

Untuk mencapai sebuah internalisasi tersebut, terdapat beberapa tahapan penting yang harus diperhatikan dalam pembinaan peserta didik. Pertama, tahap transformasi nilai. Pada tahapan ini merupakan sebuah proses yang dilakukan oleh pendidik dalam menginformasikan nilai-nilai yang baik dan yang buruk. Dengan demikian, pada tahapan ini hanya komunikasi verbal antara guru dan murid. Kedua, tahap tansaksi nilai, suatu tahap pendidikan nilai dengan sebuah jalan yang dilakukan dengan komunikasi dua arah atau interaksi antara guru dan murid yang bersifat interaksi timbal balik. Ketiga, tahap trans-internalisasi. pada tahapan ini sangat mendalam dari tahap transaksi. Pada tahapan ini bukan hanya dilakukan dengan komunikasi verbal, tetapi juga sikap mental dan kepribadian sehingga komunikasi kepribadian berperan aktif. ${ }^{9}$ Dengan demikian, dalam menginternalisasi sebuah nilai harus memiliki tahapan-tahapan sehingga membuahkan hasil yang diinginkan oleh guru terhadap muridnya.

Adapun sumber nilai kehidupan manusia dapat dibagi menjadi dua. Pertama, nilai Ilahiyah, yakni nilai yang

8 Achlami, "Internalisasi Kajian Kitab Akhlak Tasawwuf dan Pendidikan Karakter di Pesantren al-Hikmah Bandar Lampung.”

9 Achlami. diberikan oleh Tuhan dengan melalui para utusan-utusannya yang berupa iman, takwa dan adil yang diabadikan dalam wahyu Ilahi. Nilai-nilai Ilahi ini tidak akan mengalami sebuah perubahan meskipun kehidupan terasa terus berkembang mengikuti perubahannya.

Konfigurasi dari nilai-nilai Ilahi ini mungkin bisa dapat mengalami perubahan, akan tetapi secara intrinsik tetap berubah. Hal ini karena bila intrinsik nilai berubah maka kewahyuan dari sumber nilai yang berupa kitab suci al-Qur'an akan mengalami kerusakan. Seperti nilai keadilan, kedamaian dan penghargaan. Kedua, Nilai Insaniyah, yakni sebuah nilai insani yang menjadi tradisi-tradisi secara turun temurun dan mengikat anggota masyarakat yang mendukungnya.

Dalam pandangan Islam, semua nilai yang terdapat pada masyarakat dapat diterima atau ditolak. Terhadap nilai masyarakat ini Islam menggunakan lima klasifikasi: pertama, memelihara unsur-unsur nilai dan norma yang sudah baik; kedua, menghilangkan yang tidak baik; ketiga, menumbuhkan nilai dan norma baru yang dianggap baik; keempat, mencerna dan mendakwahkan kepada orang lain; dan kelima, memfilter agar sesuai dengan nilai-nilai dan norma-norma Islam. ${ }^{10}$

\footnotetext{
${ }^{10}$ Nuraini \& Nelly Marhayati, "Peran Tasawuf terhadap Masyarakat Modern," Analisis: Jurnal Studi Keislaman 19, no. 2 (2019): 297 320, https://doi.org/10.24042/ajsk.v19i2.3375.
} 
Jadi, pencapaian sumber nilai yang ideal akan terwujud jika antara agama dan sekolompok manusia yang melebur dalam diri seseorang dengan dukungan Ilahiyah. Sedangkan nilai-nilai dalam sekelompok orang akan menjadi sikap penolong kepada orang lain.

Menurut Schimmel, setidaknya terdapat dua ciri-ciri tasawuf. Pertama, persinggahan dan tingkatan. Pada tingkatan awal tasawuf yakni taubat dari dosa yang dilakukan. Kedua, cinta atau mahabbah, yakni makrifat dan upaya peleburan kepada Allah Swt. ${ }^{11}$

Untuk sampai kepada Allah Swt. manusia harus lebih dahulu mengenal dirinya sendiri yakni melalui penyucian jasmani dan rohani yang dimulai dari pembentukan kepribadian dan akhlak yang mulia. Bagi Ibnu Athoillah, tujuan tasawuf adalah menyelamatkan diri dari kesyirikan dan kebatilan, menghindari penyakit hati dengan akhlaqul karimah dan ihsan. ${ }^{12}$ Dalam ajaran tasawuf dikenal beberapa istilah pokok seperti takhalli, tahalli, dan tajalli.

\section{Takhalli}

Takhalli berarti menyucian diri dari sifat-sifat yang tercela, penyakit hati yang merusak, maksiat lahir dan batin. Hal ini karena akan menjadi penghalang

\footnotetext{
${ }^{11}$ Annemarie Schimmel, Dimensi Mistik dalam Islam, ed. Supardi Joko (Jakarta: Pustaka Firdaus, 2000).

${ }^{12}$ Ibnu Athoillah, Al-Hikam, ed. Shobirin (Jakarta: Mizan Pustaka, 2015).
}

manusia mencapai kepada Tuhannya. ${ }^{13}$ Jadi, takhalli berarti satu tahap penyucian hati, jiwa, akal pikiran yang dalam metodenya terdapat lima langkah:

a. Bersuci dari najis dengan istinjak dengan air atau tanah yang suci.

b. Berwudlu dengan air atau tayamum dengan debu yang suci.

c. Mensucikan seluruh tubuh dengan cara mandi atau menyiram dengan air yang suci.

d. Shalat taubat memohon ampunan Allah Swt.

e. Berzikir, bertauhid, dan bertahlil. ${ }^{14}$

Dengan demikian, takhalli adalah menyucikan diri dari unsur-unsur tercela dan penyakit hati seperti dengki, sombong, riya' dan semacamnya dengan taubat dan bertauhid.

\section{Tahalli}

Sedangkan tahalli adalah pembiasaan diri dengan hal-hal yang terpuji. Hal ini dimaksudkan sebagai upaya untuk melatih jiwa dan demi kesempurnaan manusia (insan kamil). ${ }^{15}$ Latihan yang dimaksud antara lain sebagaimana firman Allah Swt. dalam QS. an-Nahl [16]: 90 berikut.

\footnotetext{
${ }^{13}$ M. Saifullah Azis, Risalah Memahami Ilmu Tasawuf (Surabaya: Terbit Terang, 2000).

${ }^{14}$ Nuraini \& Marhayati, "Peran Tasawuf Terhadap Masyarakat Modern."

${ }^{15}$ Musthafa Zahri, Memahami Ilmu Tasawuf (Surabaya: Bina Ilmu, 1997).
} 


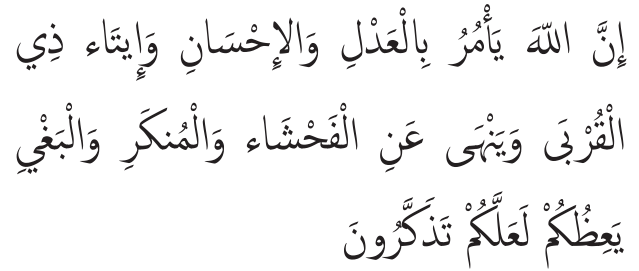

Sesungguhnya Allah menyuruh (kamu) Berlaku adil dan berbuat kebajikan, memberi kepada kaum kerabat, dan Allah melarang dari perbuatan keji, kemungkaran dan permusuhan. Dia memberi pengajaran kepadamu agar kamu dapat mengambil pelajaran. ${ }^{16}$

\section{Tajalli}

Adapun yang dimaksud dengan tajalli adalah terbukanya hijab-hijab basyariyah sehingga tampak nur Allah Swt. Atau dalam bahasa yang lain, yakni manusia mampu menggapai Tuhannya. ${ }^{17}$

\section{Internalisasi Nilai-nilai Tasawuf di Pondok Pesantren al-Amien}

Lokasi Pondok Pesantren al-Amien berada di Desa Prenduan, Kecamatan Pragaan, Kabupaten Sumenep, Jawa Timur. Tepatnya di desa pesisir antara Kabupaten Pamekasan dan Sumenep, sekitar $32 \mathrm{~km}$ di barat Pamekasan dan $22 \mathrm{~km}$ di timur Pamekasan, atau $130 \mathrm{~km}$ dari Surabaya.

\footnotetext{
${ }^{16}$ Departemen Agama RI, Al-Qur'an dan Tafsirnya II (Jakarta: Menara Kudus, 2008).

${ }^{17}$ Achlami, "Internalisasi Kajian Kitab Akhlak Tasawwuf dan Pendidikan Karakter di Pesantren al-Hikmah Bandar Lampung."
}

Berdirinya Pondok Pesantren alAmien Prenduan tidak lepas dari sosok Kiai Chotib. Beliau adalah penduduk Kampung Patapan yang belajar kepada Kiai Syarqawi di Desa Prenduan dan menikah dengan Nyai Bani, seorang penduduk asli Desa Prenduan. Pada 1879 Kiai Chotib membangun sebuah langgar kecil atau disebut congkop. Di langgar tersebut kemudian masyarakat menimba ilmu ke Kiai Chotib. Namun, Kiai Chotib meninggal pada 2 Agustus $1930 \mathrm{M}$ atau 7 Jumadil Thani $1349 \mathrm{H}^{18}$

Di tempat yang sama, Kiai Jauhari melanjutkan perjuangan ayahnya. Putra almarhum Kiai Chotib ini lalu mendirikan pondok pesantren pada 10 November $1952 \mathrm{M}$ atau 9 Dzul Hijjah $1371 \mathrm{H}$ yang diberi nama Pondok Tegal. Pada perkembangannya pondok ini menjadi Pondok Pesantren al-Amien Prenduan yang dirintis oleh Kiai Chotib dan didirikan oleh Kiai Jauhari. ${ }^{19}$

Berikut ini internalisasi nilai-nilai tasawuf dalam pendidikan di Pondok Pesantren al-Amien Prenduan:

\section{Nilai Ilahi}

Seperti halnya pondok pesantren lain, Pondok Pesantren al-Amien juga mengajarkan agar para santrinya menerapkan ajaran Islam. Dari shalat jamaah,

${ }^{18}$ Muhammad Idris Jauhari, Pondok Pesantren al-Amien dalam Lintas Sejarah (Sumenep: Al-Amien Printing, 1997).

${ }^{19}$ Jauhari, Anak Muda Menjadi Sufi, Mengapa Tidak? 
zikir, dan istighasah kubro di masjid, kegiatan santri dibimbing oleh para ustaz pondok pesantren. Begitu pula santri selama 24 jam dipantau, mulai dari pukul 03.00 WIB shalat tahajud, mengaji, sekolah, dan kegiatan intrakurikuler, ko-kurikuler, ekstrakurikuler, program bimbingan, dan kelompok (halaqoh).

Selain itu, kiai pengasuh, para ustaz dan pengurus di pondok pesantren ini juga menjadi teladan bagi para santri. Oleh karena itu, semua pihak berperan dalam internalisasi nilai-nilai tasawuf di Pondok Pesantren al-Amien.

\section{Nilai Insani}

Nilai insani berarti nilai kemanusiaan (mu'amalah ma'a naas) yang dimiliki oleh para santri supaya mereka menjadi pribadi yang welas asih kepada sesamanya. Hal ini bermakna bahwa para santri pondok pesantren dididik agar mempunyai akhlak yang terpuji. Proses internalisasi dilakukan dengan pembelajaran kitab kuning setiap selesai shalat Subuh.

\section{Faktor Pendukung dan Penghambat Internalisasi Nilai-nilai Tasawuf di Pondok Pesantren al-Amien}

Berikut ini akan diuraikan beberapa faktor pendukung dan faktor penghambat dalam proses internalisasi nilai-nilai tasawuf di Pondok Pesantren al-Amien. Kendati demikian, semua pihak di pon- dok pesantren berusaha untuk melakukan yang terbaik dan saling mendukung sama lain.

Adapun faktor pendukung dalam proses internalisasi nilai-nilai tasawuf di Pondok Pesantren al-Amien meliputi:

\section{Strenght (Kekuatan)}

Dalam penyelenggaraan kegiatankegiatan penting di pondok pesantren bermula dari musyawarah bersama baik kiai, para pengurus, dan ustaz sehingga dalam pelaksanaannya dapat maksimal, terutama pada proses pendampingan yang dilakukan selama 24 jam dan pada aspek keteladanan kiai pengasuh, para ustaz, dan pengurus pondok pesantren.

\section{Opportunity (Peluang)}

Dalam internalisasi nilai-nilai tasawuf di Pondok Pesantren al-Amien dapat dilihat dari upaya membentuk santri agar mempunyai akhlak mulia dan gemar ibadah. Oleh karena itu, pondok pesantren terbuka seluas-luasnya kepada semua kalangan masyarakat supaya memasukkan anak-anaknya ke dalam lembaga pendidikan ini. Pondok pesantren menerima semua anak dari berbagai latar belakang yang beragam suku, bahasa, daerah, ekonomi, pendidikan, sosial, dan budaya. Perbedaan ini pada dasarnya merupakan rahmat dan karunia yang perlu disikapi secara baik.

Selain adanya faktor pendukung, juga terdapat faktor penghambat dalam 
menginternalisasi nilai-nilai tasawuf di pondok pesantren antara lain:

\section{Weakness (Kelemahan)}

Faktor yang justru melemahkan proses internalisasi nilai-nilai tasawuf di Pondok Pesantren al-Amien adalah kondisi internal santri sendiri. Hal ini karena masih ada sebagian santri yang tidak mengikuti aturan-aturan yang diterapkan di pondok pesantren. Namun, pelanggaran kedisiplinan merupakan salah satu proses pendidikan bagi pendidikan. Meski demikian, para pengurus dan ustaz terus mengantisipasi dan memperketat pengawasan serta pendampingan kepada para santri pondok pesantren.

\section{Threats (Ancaman/Tantangan)}

Sedangkan ancaman dalam proses internalisasi nilai-nilai tasawuf di Pondok Pesantren ini antara lain persoalan yang dibawa dari keluarga para santri, misalnya santri yang orang tunya bercerai dan orang tuanya yang bekerja ke luar negeri. Anak santri tersebut pada dasarnya kurang kasih sayang dan perhatian dari orang tua mereka. Hal ini biasanya membuat mereka sulit mengikuti peraturan dan kegiatan-kegiatan di pondok pesantren.

\section{Simpulan}

Berdasarkan penjelasan yang telah diuraikan di atas, maka terdapat dua hal yang dapat peneliti uraikan sebagai berikut. Pertama, proses internalisasi nilai-nilai tasawuf di Pondok Pesantren al-Amien dilakukan dengan menanamkan nilai Ilahi seperti shalat jamaah, istighosah, dan lain-lain; dan nilai insani seperti ukhuwah Islamiah, solidaritas, dan kekompakan.

Kedua, beberapa faktor pendukung dalam internalisasi nilai-nilai tasawuf di pondok pesantren adalah pendampingan dan pendidikan selama 24 jam khususnya untuk memotivasi para santri agar mereka memiliki akhlak yang baik. Sedangkan penghambat dari internalisasi nilai-nilai tasawuf ini yakni adanya sebagian para santri tidak patuh atau tidak disiplin dalam menjalankan peraturan pondok dan juga karena keragaman latar belakang keluarga para santri yang berbeda-beda.

\section{Daftar Pustaka}

Azis, M. Saifullah. Risalah Memahami Ilmu Tasawuf. Surabaya: Terbit Terang, 2000.

al-Banna, Hasan. Risalah Ilaa as-Shabab. Mesir: Daar As-Shihab, 1977.

Berger, Peter L. Langit Suci, edited by Muhaimin. Yogyakarta: Rosdakarya, 2001.

Departemen Agama RI. Al-Qur'an dan Tafsirnya II. Kudus: Menara Kudus, 2008. 
Jauhari, Muhammad Idris. Anak Muda Menjadi Sufi, Mengapa Tidak? Sumenep: al-Amien Printing, 2003.

- Pondok Pesantren al-Amien dalam Lintas Sejarah. Sumenep: al-Amien Printing, 1997.

HS, Achlami. "Internalisasi Kajian Kitab Akhlak Tasawwuf dan Pendidikan Karakter di Pesantren Al-Hikmah Bandar Lampung." Analisis: Jurnal Studi Keislaman 18, no. 1 (2018). https://doi.org/10.24042/ajsk. v18i1.3302.

Hosna, Rofiatul. "Internalisasi NilaiNilai Tasawuf dalam Shalawat Wahidiyah bagi Pembentukan Karakter Mulia: Studi Kasus di SMK Ihsanniat Rejoagung Ngoro Jombang." FITRAH: Jurnal Kajian Ilmu-Ilmu Keislaman 4, no. 1 (2018). https://doi.org/10.24952/ fitrah.v4i1.877.

Ibnu Athoillah. Al-Hikam, edited by Shobirin. Jakarta: Mizan Pustaka, 2015.

Kuswandi, Iwan. KH. Muhammad Idris Jauhari: Sang Konseptor Pendidikan. Yogyakarta: Ladang Kata, 2015.

Marhayati, Nelly. "Peran Tasawuf terhadap Masyarakat Modern." Analisis: Jurnal Studi Keislaman 19, no. 2 (2019). https://doi.org/ 10.24042/ajsk.v19i2.337.
Nasr, Hossein. Islam dan Nestapa Manusia, edited by Anas Mahyuddin. Bandung: Pustaka Mulia, 1983.

Schimmel, Annemarie. Dimensi Mistik Dalam Islam, edited by Supardi Joko. Jakarta: Pustaka Firdaus, 2000.

Zahri, Musthafa. Memahami Ilmu Tasawuf. Surabaya: Bina Ilmu, 1997. 
